Olusola and Adeniji Afr. J. Infect. Dis. (2014) 8(2): 44 - 49

http://dx.doi.org/10.4314/ajid.v8i2.6

\title{
MOLECULAR DETECTION OF MEASLES VIRUS FROM CHILDREN DURING A SPORADIC OUTBREAK IN TWO SEMI-URBAN AREAS IN NIGERIA
}

\author{
B. A. Olusola ${ }^{1}$, J. A. Adeniji ${ }^{1,2}$ \\ ${ }^{1}$ Department of Virology, University of Ibadan, Nigeria, ${ }^{2}$ WHO National Reference Polio Laboratory, Department of \\ Virology, University of Ibadan, Nigeria. \\ *Email: adek1808@yahoo.com
}

\begin{abstract}
Background: According to the World Health Organization (WHO), African region accounts for $36 \%$ of deaths caused by measles worldwide. Nigeria has, over the years, recorded the highest average annual measles incidence per 100,000 populations in Africa. Measles epidemics have consistently been reported in northern Nigeria, but not in the South; reports of reduced protective haemagglutination inhibition antibody titers among children in Ibadan, southern Nigeria was made. Investigation of the viral agent responsible for the disease outbreak among children presenting with rash in two semi urban areas in southern Nigeria was carried out to confirm the etiology of the disease.

Methodology: Twenty six throat swabs (TS), and nineteen urine samples were collected from twenty six children residing in Onireke and Sabo areas of Ibadan following the report of an outbreak of rashes among children. Active case finding with the support of community leaders was used to locate the affected children. Multiplex reverse transcriptase polymerase chain reaction (MRT-PCR), was used to identify the agent.

Results: 21 of the 26 children screened tested positive for measles virus, but none was positive for Rubella virus. There was significant association between measles infection, and households with higher number of persons.

Conclusion: Mass measles vaccination that targets overcrowded, rural and inaccessible areas is needed to increase herd immunity. Public health enlightenment on the benefits of vaccination is encouraged.
\end{abstract}

Key words: Measles, vaccination, Southern Nigeria, Multiplex, PCR, urine.

\section{Introduction}

Measles has been a highly communicable disease affecting children given the absence of immunization (Black, 1989). Measles virus (MV), Rubella virus (RUBV), and Parvovirus B19 (B19V), are common causes of exanthema (Bolognia et al., 1994). Other differential diagnoses are dengue fever, enterocytopathogenic human orphan (ECHO), virus, Coxsackie virus, Herpes virus 6, bacterial and rickettsial diseases. Also, Kawasaki's disease, toxic shock, and drug reactions confound clinical diagnosis (WHO, 2000).

Although mild rash illness posses as the usual clinical feature of these infections; secondary respiratory infections due to opportunistic bacterial pathogens are frequent with measles because of the transitory immunodeficiency caused by MV. Introduction of measles into virgin populations and endemic transmission in populations with inadequate medical care is associated with high mortality (Griffin, 2007).

Measles elimination has been sustained in the United States and Europe since 2002. Eastern Mediterranean and Western Pacific regions have taken steps to achieve this on or before 2015. In 2009, the African region adopted the measles elimination goal with 2020, as the target (CDC, $2009 ; 2011)$. Vaccination of children against measles led to about $74 \%$ reduction in deaths associated with measles worldwide from an estimated 535,300 deaths in 2000 , to 139,300 in 2010 . Sub-Saharan African countries made good progress, reducing deaths rates by about $85 \%$ within this period (Simons et al., 2012).

Supplemental immunization activities were done between 2005, and 2006, in the northern and southern parts of Nigeria respectively with a follow-up vaccination in 2008 (Weldegebriel et al., 2011). However, pockets of measles outbreak continued to occur in urban cities within the country where vaccine coverage is assumed to be high (Onoja et al., 2013).

More than half of the deaths caused by measles worldwide occurred in Africa which reveals frequent outbreaks due to low vaccine coverage, failed vaccination attempts owing to quality control problems like cold chain preservation and ineffective measles surveillance (Kremer et al., 2010). Nigeria, the most populous nation in Africa with an estimated population of 166.2 million people and a birth rate of 35.51 births/1,000 population according to the 2011; estimate (CIA, 2012). In 2011, confirmed measles cases were 17,248, with an annual incidence rate of 18.2 per 100,000 children (FMOH, 2013]. Epidemics are annually reported in northern Nigeria but rarely in the southern part of the country. Since there are other conditions that present with similar clinical signs in measles virus infection, measles complications and deaths arise often due to false diagnosis. Overcrowding remains a major factor in the transmission of measles in early life in children and its severity among all age groups in certain communities (Aaby, 1984; 1984; Kamushiga et al., 2003).

Measles has been known to be highly contagious and transmitted through aerosol droplets from the nose, mouth or throat of infected persons (Yanagi et al., 2006). In this study, we confirmed the viral aetiology of a sporadic maculopapular rash infection in semi-urban populations of Onireke and Sabo areas of Ibadan Northwest Local Government Area (LGA), using multiplex reverse transcriptase polymerase chain reaction (MRT-PCR). We also investigated the association between the number of persons per household and spread of the causal agent.

\section{Materials and methods Study Area}

The outbreaks occurred in Sabo and Onireke areas of Ibadan Northwest L.G.A, with a population of about 152,834, as at 2006, census, and covers a land mass of about $26 \mathrm{~km}^{2}$. The population density is 4,870 persons per $\mathrm{km}^{2}$. Sabo area has a population of about 8,635 with 800 houses and eleven persons per household while Onireke has a population of about 5,850 with 835 houses and seven persons per household (NMSF, 2006). 


\author{
http://dx.doi.org/10.4314/ajid.v8i2.6
}

Persons living in the L.G.A are mainly middle income earners. Inhabitants of Sabo comprise majorly Hausa settlers and a few Yorubas. They live in nucleated settlements according to their religious and cultural inclinations.

On the other hand, residents of Onireke are mainly Yorubas. Onireke has a low population density because of the single family structure with enough recreation and open spaces round the buildings.

\title{
Study Population
}

Twenty six children between the ages of 0-5, years were involved in the outbreak. Eight (31\%), were less than a year while 15 (58\%), were less than 2 years old. Numbers of males were 18 with mean age of 1 year $7 \mathrm{mnths} \pm 11.6$ months (SD), while females were 8 , with mean age 2 years 2 months \pm 4 months (S.D.). They all had prodromal signs of fever with cough, coryza and/or conjunctivitis.

\section{Sample collection and Processing}

Measles cases were ascertained using the standard WHO clinical case definition: any person presenting with history of fever $\left(39-41^{\circ} \mathrm{C}\right)$, generalized macular-papular rash lasting 1-3 days and one of the following coryza, croup and conjunctivitis (WHO, 1999; Wharton et al., 1990). All the persons recruited were children co-incidentally and they presented with macular-papular rash not more than 3 days before sample collection. Ethical clearance was obtained and parental consent sought before samples were collected. A total of 45 specimens were collected from the 26 children involved in the outbreak.

Throat swab and urine samples were collected from 19 cases while only throat swabs were collected from 7 cases. Vaccination cards were not provided and we could not obtain the vaccination history from parental recall. The throat and urine sample collection and processing were according to the WHO's recommendation (WHO, 2000). We identified cases by active case finding in the Local Government area in collaboration with community leaders. Clinic and Local Government surveillance referrals were not used for case identification.

\section{Nucleic acid extraction}

QIAamp Viral RNA Mini Kit (QIAGEN, Hilden, Germany), was used to extract nucleic acid according to the procedure recommended by the manufacturer. The 45 nucleic acid extracts were kept at $-75^{\circ} \mathrm{C}$ until analyzed.

\section{Multiplex reverse transcriptase PCR Analysis}

Specific cDNA was prepared using oligo (dT), and reverse transciptase superscript III (Invitrogen, Merelbeke, Belgium), as described in previous studies (Kremer et al., 2010). Primers designed for the conserved regions of the nucleoprotein (NP), and glycoprotein (E), genes of MV and RUBV respectively were used. Their melting temperatures were very close and they operated optimally under same buffering conditions. The nucleotide sequences of oligonucleotide primer pairs used for MV NP gene are 5'-GCCATGGGAGTAGGAGTGGAAC-3' \& 5'CTGGCGGCTGTGTGTGGACCTG-3' according to kremer et al., (2010) while for RUBV E1 glycoprotein GGCAGTTGGGTAAGAGAC-3' \& 5'-CGGTGGCGAGTTTGCGTG-3' were used according to Hubschen et al., (2008).

The RT-PCR was performed in a total volume of $25 \mu \mathrm{L}$ that contained $0.9 \mathrm{mM} / \mathrm{L} \mathrm{MgCl}_{2}$,

$1 \times$ PCR buffer, $0.4 \mathrm{mM} / \mathrm{L}$ dNTPs (deoxynucleoside triphosphates), $0.3 \mathrm{U}$ Platinum taq (invitrogen), and $0.625 \mu \mathrm{M} / \mathrm{L}$ forward and reverse primers (Eurogentec, Seraing, Belgium). Reverse transcriptase PCR was then performed on isolates according to Kremer et al., (2010). However, reagents concentrations, cycling times and temperatures were optimized for this reaction since only a single round was performed. Each reaction tube contained $5 \mu \mathrm{L}$ of samples in a thermocycler (Applied Biosystems, Foster City, CA, USA). Cycling conditions for multiplex RT-PCR were $48^{\circ} \mathrm{C}$ for 45 mins and $94^{\circ} \mathrm{C}$ for 5 mins, followed by 39 cycles at $94^{\circ} \mathrm{C}$ for $30 \mathrm{~s}$ and $72^{\circ} \mathrm{C}$ for $1 \mathrm{~min}$.

\section{Sizing and analysis of amplicons using gel electrophoresis}

Expected size of the amplicon was $660 \mathrm{bp}$ for MV and 316bp for RUBV. Two percent agarose gel containing $0.5 \mu \mathrm{g} / \mathrm{mL}$ SYBR Safe $\mathbb{C}$ Invitrogen was used. TBE ( $0.089 \mathrm{M}$ Tris base, $0.089 \mathrm{M}$ boric acid, 1mM EDTA), was used as the electrophoresis buffer. Applied voltage for electrophoresis was 220 volts for 1 hour 30 minutes. Results were photographed using Gel documentation system.

\section{Results}

Out of the 45 samples collected, MV was confirmed in 25 of them as shown in Fig 1, where the expected band size is 660bp and $316 \mathrm{bp}$ for RUBV. Twenty one out of the 26 children screened were positive for Measles infection while none was positive for rubella. Nineteen samples were positive out of the 26 throat swabs while 6 samples were positive out of the total 19 urine samples as shown in the tables above. There was a significant association ( $\mathrm{p}=0.025$ ) between the presence of $\mathrm{MV}$ and high number of persons per households.

Table 1: showing the total number of persons positive for measles infection on location basis

\begin{tabular}{|l|l|l|l|}
\hline Number of persons screened for measles infection & Sabo & Onireke & Total \\
\hline Positive & 1 & 20 & 21 \\
\hline Negative & 5 & - & 5 \\
\hline Total & 6 & 20 & 26 \\
\hline
\end{tabular}


http://dx.doi.org/10.4314/ajid.v8i2.6

Table 2: showing the summary of positive measles infection based on sample type

\begin{tabular}{|l|l|l|l|}
\hline Number of samples screened for measles infection based on sample type & Urine & Throat swab & Total \\
\hline Positive & 6 & 19 & 25 \\
\hline Negative & 13 & 7 & 20 \\
\hline Total & 19 & 26 & 45 \\
\hline
\end{tabular}
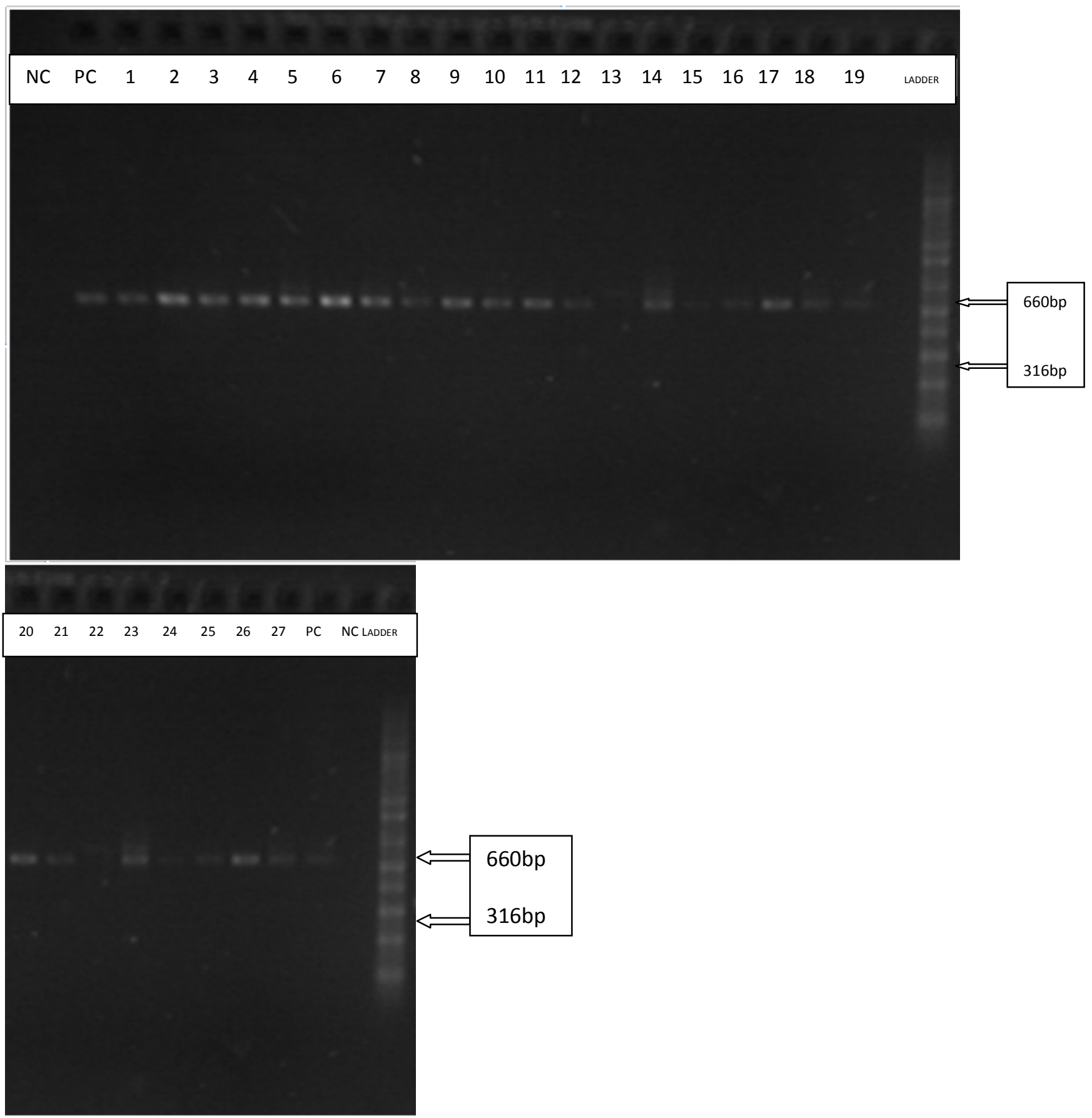

Figure 1: PCR amplicons on gel lanes showing 660bpMV band size

Figure 1., shows the PCR amplicons on gel lanes. Each lane represents a sample from a person recruited in the study while lane 27 is a urine sample that was re run to ascertain MV presence. No Rubella positive control was used during the experiment as band size detection on gel at $316 \mathrm{bp}$ and 660 bp is confirmatory for rubella and measles respectively. DNA ladder (100bp), was used for detection as shown while measles positive control is shown in lane 2 and lane 28. 
Table3: showing the proportion (in \%) of persons positive for Measles virus infection on multiplex RT-PCR for urine and throat swab samples in both locations

\begin{tabular}{|l|l|l|l|l|}
\hline Location & $\begin{array}{l}\text { Total number of } \\
\text { urine samples }\end{array}$ & $\begin{array}{l}\text { Total } \\
\text { number of } \\
\text { throat swab } \\
\text { samples }\end{array}$ & $\begin{array}{l}\text { Number(\%) positive for urine } \\
\text { samples }\end{array}$ & $\begin{array}{l}\text { Number(\%) } \\
\text { positive } \\
\text { throat swab } \\
\text { for }\end{array}$ \\
\hline Sabo & 19 & $\mathbf{1 9}$ & - & $18(94.7 \%)$ \\
\hline Onireke & - & $\mathbf{2 6}$ & & $1(14.28 \%)$ \\
\hline Total & 19 & & \\
\hline
\end{tabular}

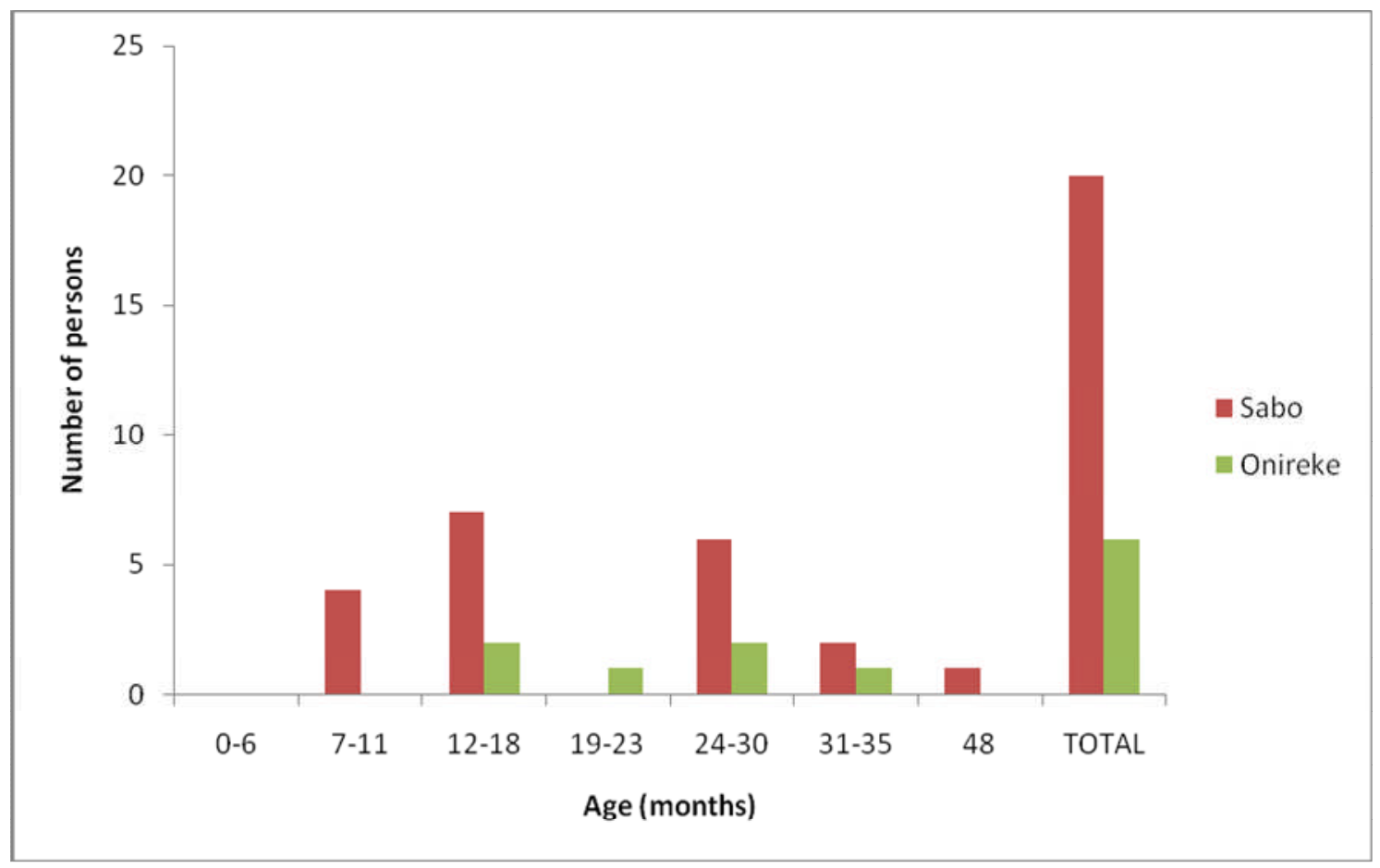

Figure 2: Distribution of samples collected according to age group and location

\section{Discussion}

The results of this study showed that the disease outbreak was due to MV and not RUBV. This proves that measles is still endemic in Nigeria despite ongoing vaccination programs (Adu et al., 1992). That measles was diagnosed in these semi-urban populations of Oyo State, was quite significant; but no report was made by the national centre for disease prevention and control in the period under study. The use of MRT-PCR in this investigation is ideal in ruling out differential diagnosis of Rubella which could have confounded diagnosis and prevented the treatment of appropriate symptoms; this observation has been identified in previous studies by Rota et al., (2011).

Although, IgM remains the gold standard for measles identification, serological techniques have certain drawbacks that made it really unuseful in this study. These drawbacks include unwillingness of mothers to consent to bleeding of sick children for blood sample collection, inability of the test to rule out both measles and rubella in a single assay and the need to collect blood 14 days after for IgG confirmation. These challenges were overcome by the MRT-PCR method used as there was no need to collect blood and the assay could differentiate both infections in a single round.

Prior to the use of this method in our laboratory, tissue culture was employed to investigate viral rash infections among children and despite the fact that results were inconclusive; the technique was also more laborious. In spite of reported vaccination coverage in Ibadan, outbreak of measles still occurred. This points to the fact that the critical community size for the virus maintenance is been exceeded (Rohani, 1999), and that the heterogeneous nature of the population should be put into consideration during future vaccination programmers (Fox et al., 1971).

94.7\% of children from Sabo from whom throat swabs were collected were confirmed positive for measles, these observations, agrees with works done on TS for Measles virus detection (VanBinnendijk, 2003; Mosquera et al., 2006). This shows that multiplex RT-PCR technique for measles detection ultimately improves the turnaround time for laboratory confirmation and characterization of Measles virus instead of collection of two phase blood specimens at 14days interval along with another specimen.

The proportion of positive samples (31\%) detected from urine in Sabo community was considerable being the first time urine samples would be used for measles identification using a multiplex RT-PCR technique in Nigeria. The urine samples collected were early morning voided urine and were processed as instructed in WHO laboratory manual for measles diagnosis. To the best of our knowledge, this is the first time, Measles virus was 


\author{
Olusola and Adeniji Afr. J. Infect. Dis. (2014) 8(2): 44 - 49 \\ http://dx.doi.org/10.4314/ajid.v8i2.6
}

detected from urine samples collected from subjects residing in the southern part of the country. However, may be more urine samples would have been positive if two rounds nested PCR was done as against the single round done in this work.

In considering settlement patterns, the frequency of infection was higher in Sabo compared to Onireke, this supports the claim that overcrowding remains a risk factor for measles transmission. Association does not mean causation. Number of persons per household serves as good indicators for overcrowding. The average number of persons per household in the houses where children were positive for measles infection in Sabo is eleven while that of Onireke is as low as five. It must also be stated that these two areas are under the same surveillance district. Moreover, cases were identified by active case finding in collaboration with community leaders without the use of clinical or health officers' referrals. Association between overcrowding and measles infection was an observation based on the areas affected and the number of persons identified not that the study was designed to test the hypothesis.

Rural-urban drift and high birth rate has increased the housing problem thereby swelling up the number in many townships. Children are of significant number to the total population, as such there is the likelihood of spread of MV in play groups or schools by aerosol. The socio-economic status of people in both communities is the same and they are exposed to the same environmental and health challenges.

The mean age of affected children is $\leq 2$ yrs as shown in Fig 2 which corroborates the fact that measles is a childhood problem (WHO, 2012). Attainment of the fourth Millennium Development Goal largely depends on the ability to reduce the mortality rate in these children as measles is the fifth leading cause of childhood mortality in Nigeria (WHO, 2006; 2009).

The fact that there was no evidence of vaccination and that parental recall failed to provide information on vaccination raises questions about immunization coverage in semi-urban areas. Immunization is a proxy indicator for overall access to basic health care which has been shown to be inadequate because of these pockets of infections coupled with the fact that maternal immunity might had waned at this age and herd immunity compromised (Vanden Ent et al., 2011).

\title{
Conclusion
}

The use of multiplex RT-PCR is a good method for detecting measles virus. It saved lives and prevented exposure of other children as the early detection provided enough evidence for the supplemental vaccination of the areas affected and also supportive care for the children presenting with fever and rash or who have had contact with such children in these areas. Also there is ongoing plan to document endemic areas gravely affected by vaccine preventable infectious diseases like measles infection so as to give such areas priority during supplemental vaccination programmes.

Furthermore this method will guide policy makers in developing control measures and elimination strategies. This work emphasizes the need to investigate and establish causes of outbreaks on time so that care givers can come in to help at the appropriate time (Waku-Kouomou et al., 2006). Measles can be preventable through vaccines, and as such children should be vaccinated against it by 9 months. There is need for more enlightenment on measles vaccination even in urban areas as none of the children in this study was vaccinated against the virus.

Measles immunization activities should be selective and children less than 5 years should be the main target. Focus should be on overcrowded and densely populated communities during supplemental vaccination activities as this will greatly reduce outbreaks. Although epidemics are not readily reported in southern Nigeria, there is the need to intensify and sustain immunization efforts especially among under 5 year old children in urban, semi-urban and rural populations in this part of the country to avert epidemics.

To meet up the timeline for measles reduction by 2020, sub-Saharan African countries (indeed all of Africa), should ensure vaccination cards are made compulsory requirements for entry into both public and private Nursery/ Primary schools in order to increase herd immunity among target age groups. Unless on ethical grounds which is still debatable, this approach looks suitable for Nigeria as there is no religious/ cultural bias towards measles vaccination as to what is obtainable in polio vaccination.

The major challenge to measles vaccination in Nigeria is the timing. The vaccine is administered at 9 months when almost all other vaccines are completed; hence there is reluctance in the part of nursing mothers to go for vaccination of their wards in vaccination centers. Secondly, children traveling to non-endemic countries should be checked for measles vaccination cards. Also, vaccination officials should ensure that poorly planned areas are given top priority during immunization campaigns.

\section{References}

1. Aaby, P. (1988). Malnutrition and overcrowding/intensive exposure in severe measles infection: review of community studies. Review of Infectious Diseases 10:478-491.

2. Aaby, P. (1984). Overcrowding and intensive exposure as determinants of measles mortality. American Journal of Epidemiology 120:49-60.

3. Adu, F.D., AAkinwolere, O.A.O., Tomori, O., and Uche, L.N. (1992). Low seroconversion rates to measles vaccination among children in Nigeria. Bulletin of World Health Organization. 70:457-60.

4. Black, F.L. (1975). Infectious disease in primitive societies. Science 187:515-518.

5. Black, F.L. (1989). Measles active and passive immunity in a worldwide perspective. Progress in medical virology 36:1-33.

6. Bolognia, J., and Braverman, I.M. (1994). Skin manifestations of internal disease. In Principles of internal medicine, 13 ${ }^{\text {th }}$ Ed. Vol. 1. Isselbacher, K. J., Braunwald, E., Wilson, J.D., Martin, J.B., Fauci, A.S., and Kasper, D.L. (eds.). McGraw-Hill Book Company, New York, NY p300.

7. Center for Disease Prevention and Control (2011).. Measles Outbreaks and Progress towards Measles Preelimination - African Region, 2009 -2010. Morbidity\& Mortality Weekly Report 60(12):374-378.

8. Center for Disease Prevention and Control (2009). Progress toward the 2012 Measles Elimination Goal -Western Pacific Region, 1990 -2008. 58(24):669-673.

9. CIA World Factbook (2012). Nigeria birth rate 2012. https://www.cia.gov/library/publications/the-world-factbook/index.html.

10. Federal Ministry of Health (FMOH) (2013). Weekly Epidemiology Report, Nigeria Centre for Disease Control (NCDC) 3(7):1-11

11. Fox, J.P., Elveback, L., Scott, W., Gatewood, L., and Ackerman, E. (1971). Herd immunity: basic concept and relevance to public health immunization practices. American Journal of Epidermiology 94:179-89. 


\section{http://dx.doi.org/10.4314/ajid.v8i2.6}

12. Griffin, D.E. (2007). Measles virus. In: Fields Virology, 5th Ed, D. M. Knipe, P. M. Howley (Eds), Philadelphia: Lippincott Williams \& Wilkins p1551.

13. Hubschen, J.M., Kremer, J.R., De Landtsheer, S., and Muller, C.P. (2008). A multiplex taqman PCR assay for the detection of measles and rubella virus. Journal of virological methods. 149: 246-250.

14. Kamugisha, C., Cairn, K.L., and Akim, C. (2003). An outbreak of measles in Tanzanian refugee camps. Journal of Infectious Disease 187:58-62.

15. Kremer, J.R., Nkwembe, E., Oyefolu, A.O.B., Smith, S.B., Pukuta, E., Omilabu, S.A., Adu, F.A., Tamfum, J.M., and Muller, C.P. (2010). Measles virus strain diversity, Nigeria and Democratic Republic of the Congo. Emerging Infectious Diseases16:1724-30.

16. Morley, D., Martin, W., and Allen, I. (1967). Measles in east and central Africa. East Africa Medicine 44:497-508.

17. Mosquera, M.M., Ory, F., Gallardo, V., Cuenca, L., Morales, M., Sánchez-Yedra, W., Cabezas, T., Hernández, J,M., and Echevarría, J.E. (2006). Evaluation of Diagnostic Markers for Measles Virus Infection in the Context of an Outbreak in Spain. Journal of Clinical Microbiology 3:5117-21.

18. Nigeria/Africa masterweb special feature (NMSF) Nigeria (2006) census Figures. South census Figures. Available at: www.nigeriamasterweb.com/NigeriacensusFigs.html

19. Onoja, A.B., and Adeniji, J.A. (2013). Kinetics of measles antibody by Haemagglutination Inhibition Assay (HIA) in children in a south-west and north-central Nigerian State. International Journal of Infectious Disease. doi:10.1016/j.ijid.2013.02.001.

20. Rohani, P., Earn, D.J., and Grenfell, B.T. (1999). Opposite patterns of synchrony in sympatric disease metapopulations. Science 286(5441): 968-71.

21. Rota, P.A., Brown, K.E., Hübschen, J.M., Muller, C.P., Icenogle, J., Chen, M., Bankamp, B., Kessler, J.R., Brown, D.W., and Bellini, W.J., (2011). Featherstone D. Improving Global Virologic Surveillance for Measles and Rubella. Journal of Infectious Disease 204: 506-513

22. Rota, P.A., Khan, A.S., Durigon, E., Yuran, T., Villamarzo, Y.S., and Bellini, W.J. (1995). Detection of measles virus RNA in urine specimens from vaccine recipients. Journal of Clinical Microbiology 33(9):2485.

23. Schimmer, B., and Ihekweazu, C. (2006). Polio eradication and measles immunization in Nigeria. Lancet Infectious Disease 6:63-65.

24. Simons, E., Ferrari, M., Fricks, J., Wannemuehler, K., Anand, A., Burton, A., and Strebel, P. (2012). Assessment of the 2010 global measles mortality reduction goal: results from a model of surveillance data. Lancet 379:2173-78.

25. Van Binnendijk, R.S., van den Hof, S., Van den Kerkhof, H., Robert, H.G., Woonink, K.F., Guy, A.M., Marina, A.E., Van Spaendonck, C., and Tjeerd, G.K. (1993). Evaluation of Serological and Virological Tests in the Diagnosis of Clinical and Subclinical Measles Virus Infections during an Outbreak of Measles in the Netherlands. The Journal of Infectious Diseases 188:898-903.

26. Van den Ent., Brown D.W., Hoekstra E.J., Christie A., and Cochi S.L. (2011). Measles mortality reduction contributes substantially to reduction of all cause mortality among Children less than five years of age, 1990-2008. The Journal of Infectious Diseases 204:18-23

27. Waku-Kouomou, D., Alla, A., Blanquier, B., Jeantet, D., Caidi, H., Rguig, A., Freymuth, F., and Wild, F.T. (2006). Genotyping Measles Virus by Real-Time Amplification Refractory Mutation System PCR Represents a Rapid Approach for Measles Outbreak Investigations. Journal of Clinical Microbiology. 44(2): 487-494.

28. Weldegebriel, G.G., Gasasira, A., Harvey, P., Masresha, B., Goodson, J.L., Pate, M.A., Abanida, E., and Chevez, A. (2011). Measles resurgence following a nationwide measles vaccination campaign in Nigeria, Journal of Infectious Disease 204:226-231.

29. Wharton, M., Chorba, T.L., Vogt, R.L., Morse, D.L., and Buehler, J.W. (1990). Case definitions for public health surveillance. Morbidity and Mortality Weekly Report Recommendations and Reports 39:1-43.

30. World Health Organization (1999). WHO guidelines for epidemic preparedness and response to measles outbreaks. WHO/CDS/CSR/ISR/99. Available: www.who.int/csr/resources/publications/measles/WHO_CDS_CSR_99_1/en

31. World Health Organization (2001). Manual for the laboratory diagnosis of measles virus infection WHO/V\&B/00.16 Geneva, Switzerland1-49.

32. World Health Organization (2009). Measles vaccines: WHO position paper. Weekly Epidermic Report 84:349-60.

33. World Health Organization (2006). Progress in global measles control and mortality reduction. 2000-2006. Weekly Epidermic Report 81:365-71.

34. World Health Organization (2013). Reported measles cases and incidence rates by WHO member states 2010 and 2011. http://www.who.int/mediacentre/news/notes/2013/measles_20130117/en/

35. World Health Organization (1993).. The immunological basis for immunization. Module 7: Measles, Cutts FT (Ed) Geneva, Switzerland p1-28.

36. Yanagi, Y., Takeda, M., and Ohno, S. (2006). Measles virus: cellular receptors, tropism and pathogenesis. Journal of General Virology 87:2767-79. 